\title{
Protein-binding assays for adrenocorticoids
}

ROBERT E. BOWMAN and RAUL F. DE LUNA, UNIVERSITY OF WISCONSIN PSYCHOLOGY DEPARTMENT and WISCONSIN REGIONAL PRIMATE RESEARCH CENTER, Madison, Wisc. 53706

The measurement of the adrenocortical hormones, cortisol and corticosterone, in blood plasma has previously best been done by procedures employing varying degrees of purification of the hormone, followed by photometric or fluorimetric quantitation. These methods have been relatively difficult or laborious, particularly in the case of the procedures that most specifically measure the hormone of intent. These limitations are considerably overcome by new assays for cortisol and corticosterone based on the principle of competitive proteinbinding of the steroids in the presence of radioactively labeled steroid of the same molecular species. These methods are described and data on the specificity of such a method for corticosterone are presented and compared with one of the better fluorimetric assays.

Numerous studies in the psychological literature have utilized measurements of cortisol and corticosterone in blood plasma as endocrinological indices related to stress. These steroids have typically been measured by extracting them from plasma and purifying them to varying extents by solvent partitions or by chromatography, following which they are reacted with acids or other reagents to produce molecular species that may be quantified by the amount of fluorescence or absorbance of light they exhibit. These basic procedures have been described by Polidora and Bowman (1966), and criteria (specificity, accuracy, precision, and sensitivity) by which assays may be compared have recently been quantitatively discussed by Anastassiadis and Common (1968).

There have been several limitations of the above methods in psychoendocrinological applications. Many of the methods have been scaled to require $2.5 \mathrm{ml}$ of blood plasma per sample, and are thus only marginally sensitive enough for animal research. Exceptions to this are methods using $0.5 \mathrm{ml}$ of plasma for cortisol measurements in the human or monkey (Bowman, 1967) or $0.05 \mathrm{ml}$ of plasma for corticosterone measurements in the rat or mouse (Glick, von Redlich, \& Levine, 1964).

A more serious problem has been the question of specificity of measurement; that is, the extent to which a method measures only the steroid it is intended to measure. In general, the simplest fluorescence methods for cortisol (purifying only by solvent partitions prior to fluorescence measurements) are the least specific and overestimate cortisol by as much as $40 \%$ (Tarquini \& Toccafondi, 1965; Nielsen \& Asfeldt, 1967; James, Townsend, \& Fraser, 1967). The more laborious fluorescence methods (employing chromatographic purification) appear more specific, and are equivalent in this respect to absorbance methods that utilize the Porter-Silber reaction of cortisol with pheny lhydrazine in acid-alcohol solvent (Ely, Hughes, \& Kelley, 1958; Eechaute, 1966). The specificity of Porter-Silber absorbance methods has been described by Peterson, Karrer, and Guerra (1957), who demonstrated cortisol estimates on 12 human plasmas "within $\pm 12 \%$ " of the true values, and by Bowman (1967) who found an average $25 \%$ overestimate of cortisol for 25 monkey plasmas and a $6 \%$ overestimate for a standard human plasma. Fortunately, much of the nonspecificity of both the fluorescence and absorbance methods has proven proportional to cortisol concentration, so that these methods have been useful for establishing major features of adrenocortical functioning.

Corticosterone methods have almost exclusively utilized fluorescence quantitation following solvent partition. The simplest of these procedures appear to overestimate plasma corticosterone in rat or mouse by $16-20 \%$ (Solem \& Brinck-Johnsen, 1965), and in avian plasma by $100 \%$ and more (Frankel, Cook, Graber, \& Nalbandov, 1967). As Frankel et al (1967) point out, the specificity of corticosterone methods on rat plasma has been only weakly established to be within a $5-10 \%$ overestimate of the true values.

Another serious limitation of many of the above methods, particularly those for cortisol determination, has been the expense, labor, and high level of specialized skill necessary to perform them. Only the simpler, fluorimetric methods can be considered to be within the reach of modest laboratories or of those investigators lacking extensive training or experience in quantitative biochemistry.

The advent of competitive protein-binding radioassay of steroids appears to circumvent many of the above limitations of other methods, and is the subject of the present report. Originally described by Murphy, Engelberg, and Pattee (1963), this technique has recently been considerably refined and extended by Murphy (1967). The principle is based on the fact that certain plasma proteins contain sites that relatively selectively at tach or bind cortisol, corticosterone, or a few other steroids. Such binding proteins appear physiologically important in the transport of steroids in the blood. Steroid molecules are continually attaching and being released from the binding sites and thus compete, in a statistical sense, for the sites. To use this property in a steroid assay, the radioactively labeled steroid is equilibrated with a binding protein so as to occupy all of its binding sites. A sample containing nonradioactive steroid is then introduced and competes for the binding sites, thus displacing radioactive steroid from the protein in an amount proportional to the concentration of nonradioactive steroid. The unbound steroid is then removed from the solution and the amount of radioactive steroid remaining bound to the protein is determined by counting radioactive disintegrations. From a graph of such counts left bound on the protein by various known concentrations of the steroid, the concentration of the steroid in a sample can be inferred from the counts it leaves bound on the protein.

This technique has been utilized in a procedure for determining cortisol (Bowman \& De Luna, 1968) and in a second procedure reported here for determining corticosterone, with the following advantages. First, the two procedures are the most sensitive currently available, and are routinely performed on plasma samples of 10 microliters $(.01 \mathrm{ml})$. Second, the two procedures utilize only a small number of simple laboratory manipulations and are thereby among the most rapid, easy, and economical of methods to perform. Third, the procedure for cortisol has been shown to be essentially specific under normal circumstances (Bowman \& De Luna, 1968), and data presented here are indicative that the corticosterone procedure has good specificity. Finally, essentially one technique, with minor 
modifications for various steroids, appears applicable to a number of steroid determinations. Certainly, the procedures applied to cortisol and corticosterone are so similar that either can be done readily once the first has been mastered. Furthermore, similar procedures have appeared in the literature for the determinations of progesterone (Yoshimi \& Lipsett, 1968), testosterone (Horton, Kato, \& Sherins, 1967; Murphy, 1968), and estrogens (Murphy, 1968). In fact, this assay method should prove applicable to any hormone for which specific receptor molecules can be isolated and it is therefore likely to become a basic and widely applied technique in coming years.

The only limitation of the protein-binding technique for some laboratories is the necessity to work with radioisotopes. Requirements for such work are maintained by a Radiation Safety Committee within each university holding an A.E.C. license. A relatively high capital outlay is also required for a scintillation counter, which is the best instrument for the radioactivity counting associated with protein-binding assays. However, the less expensive ambient temperature scintillation counters are adequate, or used counters may be available from the manufacturers at considerably reduced cost. Finally, since the counting time can be kept to $5 \mathrm{~min}$ or less per sample, it may be most economical if counting time on a cost basis can be arranged with a nearby laboratory already equipped with scintillation counters.

\section{METHOD}

\section{Cortisol Method}

Murphy (1967) measured the amount by which plasma proteins from different species bind cortisol and other steroids, and found that rabbit plasma had a binding protein with the greatest specificity for cortisol. Her data also indicated specificity for cortisol to be improved if Fuller's earth was used as an absorbent for removing unbound cortisol and other steroids from solutions following equilibration of the sample with rabbit plasma that had been previously saturated with tritiated cortisol. Using these procedures, and substituting a commercially available, lyophilized, rabbit $\alpha$-globulin for rabbit plasma, Bowman and De Luna (1968) have described a protein-binding method for cortisol measurement and have found this method to be essentially specific for cortisol when measured on 23 monkey plasmas and a standard human plasma.

\section{Corticosterone Method}

Murphy (1967) found rat and monkey plasma to be the most specific for binding corticosterone, and Florisil as an absorbent to be best for scavenging unbound corticosterone from solution. Samples were stored by pipetting 10 microliters of plasma (using a 50-microliter Hamilton syringe calibrated in 1-microliter steps) into a $3 \mathrm{ml}$ round-bottomed test tube, adding $.19 \mathrm{ml}$ of distilled water from a Repipet (Labindustries, Berkeley, Calif.), stoppering tightly and storing frozen until ready for assay. Standards of pure corticosterone were prepared by similarly pipetting aliquots of 0 , $10,20,30,40$, and 50 microliters from a solution containing exactly 0.1 microgram of corticosterone per ml of distilled water and diluting to $0.2 \mathrm{ml}$ with distilled water. These quantities of the standards were equivalent to sample corticosterone concentrations of $0,10,20,30,40$, and 50 micrograms\% (i.e., micrograms of corticosterone per $100 \mathrm{ml}$ of plasma).

A standard protein-binding solution (protein solution) was prepared by pooling enough rat (or monkey) plasma to last about 3 months and storing it frozen in 1-2 $\mathrm{ml}$ portions. One $\mathrm{ml}$ of the thawed plasma was diluted to $100 \mathrm{ml}$ with distilled water in a volumetric flask and this solution was added to a $125-\mathrm{ml}$ glass-stoppered bottle containing 19 microcuries (133 nanograms) of tritiated corticosterone (New England Nuclear, 49 curies per millimole) that had been dried from a $10 \%$ ethanol $/ 90 \%$ benzene solution at $45 \mathrm{deg} C$ under a stream of nitrogen gas. This solution was shaken well and was stored between use at 0-5 deg C. A fresh solution was prepared weekly. In practice, the exact amount of tritiated corticosterone to be combined with the protein solution depends on the corticosterone binding capacity of the plasma pool used in making the solution. Sufficient tritiated corticosterone is used so that about $80-90 \%$ of it will saturate the protein-binding sites (as discussed by Murphy, 1967).

Scintillation fluid was made to contain, per $100 \mathrm{ml}$ of solution: $38.5 \mathrm{ml}$ of xylene, $38.5 \mathrm{ml}$ of dioxane, $23 \mathrm{ml}$ of absolute ethanol, $8.09 \mathrm{~g}$ of naphthalene, $0.504 \mathrm{~g}$ of 2,5 -diphenyloxazole, and $0.00504 \mathrm{~g}$ of naphylphenyloxazole.

To perform the assay, $1.2 \mathrm{ml}$ of dichloromethane (Matheson, Coleman, \& Bell, B.P. 39.5-40.5 deg C) was added to each of six thawed samples and mixed on a Vortex mixer for $15 \mathrm{sec}$ to extract corticosterone. The phases were separated by centrifuging for $2 \mathrm{~min}$ in a small International clinical centrifuge (Model CL), and exactly $1 \mathrm{ml}$ of the dichloromethane layer was transferred to a clean $3-\mathrm{ml}$ test tube using a $2.5-\mathrm{ml}$ Hamilton syringe. The dichloromethane was evaporated at $45 \mathrm{deg} C$ under a stream of nitrogen gas. This extraction step was used mainly to separate the sample corticosterone from the sample proteins, whose corticosterone-binding capacity would otherwise interfere with the assay.

Exactly $1 \mathrm{ml}$ of cold $(5 \mathrm{deg} \mathrm{C})$ protein solution was added to each dried sample or standard extract, vortex mixed for several seconds, and stored at $5 \mathrm{deg} C$ until all tubes in the run were brought in sets of six to this stage. All tubes were then placed in a 45-deg $\mathrm{C}$ bath for $5 \mathrm{~min}$, to insure solution of the dried extracts and were then vortex mixed and kept at $5 \mathrm{deg} C$ for a minimum of $15 \mathrm{~min}$ to insure equilibration of the corticosterone with the binding protein.

Exactly $40 \mathrm{mg}$ of Florisil (60-100 mesh, Floridin Co., Tallahassee, Florida) was added to each of six tubes at $5 \mathrm{deg} C$, and the tubes were vortex mixed for exactly $30 \mathrm{sec}$ each. The Florisil adsorbed all unbound corticosterone, leaving in solution only the corticosterone bound to the protein. When all tubes had been treated with Florisil, they were brought to room temperature and a $0.50-\mathrm{ml}$ aliquot of each supernatant was pipetted into a $20-\mathrm{ml}$ scintillation vial using a $1-\mathrm{ml}$ Hamilton syringe. Each aliquot was then diluted with exactly $10 \mathrm{ml}$ of dioxane scintillation fluid and counted in a Packard Tri-Carb scintillation counter. Each vial was counted for $5 \mathrm{~min}$. The counts per minute for the standards were graphed against the concentrations of the standards, a smooth curve was drawn by eye through the points, and the concentration of each sample was determined graphically by entering this curve at the number of counts per minute observed for the sample.

\section{RESULTS}

Values obtained by the protein-binding assay for corticosterone were compared with values on the same plasma obtained by a highly sensitive fluorescence assay employing solvent partitions for purification (Glick, von Redlich, \& Levine, 1964). From plasma corticosterone values described by Glick et al (1964), their fluorescence assay appeared comparable in specificity to those assays cited by Frankel et al (1967) as presenting some evidence for no more than 5-10\% overestimation of cortisol. To obtain data in our own laboratory on specificity, the fluorescence and protein-binding assays (using monkey plasma as the source of binding protein) were performed by Beatty (1968) on adrenalectomized and dexamethasone-treated rats. For adrenalectomized rats that subsequently died when shifted from salt water to tap water (thus indicating functionally complete adrenalectomy), the fluorescence assay averaged .25 micrograms\% on six 
rats and the protein-binding assay averaged 0 micrograms $\%$. The protein-binding assay averaged 0.08 micrograms\% (range $0-.28$ micrograms\%) on those same six rats and an additional eight rats. For seven rats who subsequently survived the tap water test (thus indicating incomplete adrenalectomy), the fluorescence assay averaged 3.36 micrograms\% and the protein-binding assay averaged 3.63 micrograms\% (range 9.3 .7 micrograms\%). For 17 rats injected with 200 micrograms of dexamethasone (a synthetic steroid that suppresses ACTH secretion and therefore corticosterone secretion) per $\mathbf{k g}$ of body weight, the protein-binding assay averaged .40 micrograms\% (range $0-1.25$ micrograms $\%$ ). Since normal rat plasma contains $5-50$ micrograms\% corticosterone, it was clear that both the fluorescence and proteinbinding methods normally measure little else in rat plasma except corticosterone or other substances secreted by the adrenal cortex.

For normal rats under varying amounts of behavioral stress, the protein-binding assay and the fluorescence assay were compared in three experiments. In the first experiment using monkey plasma as the source of binding protein (Table 1), 14 rats averaged 10.6 micrograms\% by the protein-binding assay and 10.5 micrograms\% by the fluorescence assay, a nonsignificant difference. The first seven of these plasmas had been stored frozen for approximately 2 months prior to assay, and the last seven had been stored frozen for approximately 2 years. The fluorescence assay appeared to measure lower than the protein-binding method on the short-stored plasmas, and higher on the long-stored plasmas. Although these differences were not statistically significant, they were consistent with the data of the next two experiments.

Since other laboratories would find it more convenient to use rat plasma than monkey plasma as the source of binding protein, Experiment 2 was performed mainly to compare these two plasmas in the protein-binding assay. However, the fluorescence assay was also performed. Eighteen rat plasmas stored frozen for about 3 years were assayed. The initial fluorescence assay on the frozen plasmas, performed within a month of their collection, averaged 26.4 micrograms\%, and after 3 years of frozen storage averaged 35.9 micrograms\% (Table 1). The rat and monkey protein-binding assays after 3 years of frozen storage averaged 27.8 micrograms\% and 29.3 micrograms, respectively. The higher estimates of the protein-binding assays (6\% and $11.5 \%$, respectively) compared to the initial fluorescence assay may have represented either slight nonspecificity or slight increases in corticosterone concentration due to sublimation of water from the plasmas. However, the $30 \%$ increase in the fluorescence values with storage clearly represented the development of nonspecific fluorigens in these samples. Statistically, differences between the two protein-binding assays approached but did not reach significance.

The third experiment was performed to compare the rat protein-binding assay with the fluorescence assay on frozen rat plasmas stored for only a short time. The first 10 plasmas listed (Table 1, Experiment 3) were taken from rats stressed by shaking in a box and were stored frozen for less than 1 day before assay; the last 10 plasmas were taken from rats following $1 \mathrm{~h}$ of spatial $Y$-maze discrimination for water reinforcement and were stored frozen for about 1 month. These plasmas averaged 20.4 micrograms\% by the protein-binding method and 19.6 micrograms\% by the fluorescence method, a significant difference $(p<.06)$.

It can be noted that the variability between replicate determinations (listed at bottom of Table 1) was about the same for both protein-binding and fluorescence assays, with the S.D. ranging from .84 micrograms\% to 3.64 micrograms\%. However, the fluorescence assay more frequently yielded disparate

Table 1

Mean corticosterone values in $\mu \%$ estimated by fluorescence asay and by protein-binding assay using either monkey or rat plasms as the source of binding protein. In each experiment, amples of the plasma from each rat were subjocted to each of the different asays and the values are tabulated wide by side for comparivon. Each value is generally the mean of two or more replicate determinations, and the approximate average number of replicates per mean are indicated in parentheses at the top of each column.

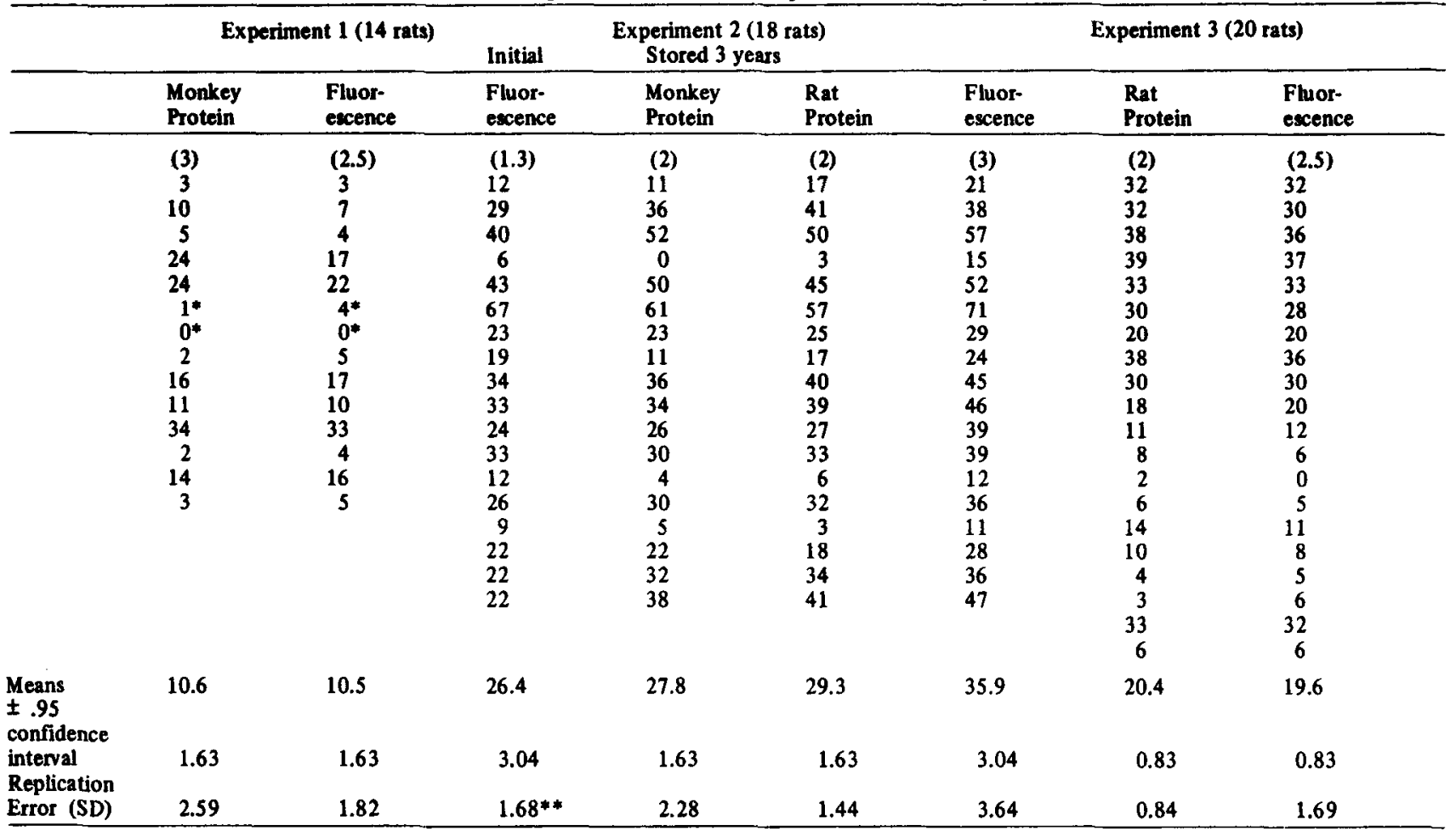

Adrenalectomized rats

**Based on only 6 duplicate determinations 
replications, which required the measurement of additional replicates to obtain more accurate mean plasma concentrations.

\section{DISCUSSION}

From all of these results, it appears that if any real difference existed between the rat protein-binding assay and the fluorescence assay, it was of the order of a $3 \%$ higher estimate by the former on fresh plasma (Table 1, Experiment 3). For all practical purposes, therefore, the specificity of these methods appeared equivalent on fresh plasma. If the plasma was stored frozen for $2-3$ years before assay, the specificity of the fluorescence method, but not of the protein-binding method, was compromised.

These data do not firmly establish the absolute specificity of the protein-binding method for corticosterone, as has been done for cortisol on a representative set of samples (Bowman \& De Luna, 1968), but they do establish the specificity as being not appreciably worse than that of a fluorescence assay of the type used by most present workers to measure corticosterone. The data on adrenalectomized and dexamethasone-treated rats further indicate that any nonspecificity would mainly represent substances secreted by the adrenal cortex, and thus would likely be proportional to adrenal cortical function. In addition, the close correspondence of both protein-binding and fluorescence values on each plasma provides at least suggestive evidence of good specificity for both assays, since any interfering substances would have had to mimic corticosterone to about the same degree in both of the two assays, and each assay depended on possession of quite different chemical properties by the molecular species being measured.

Aside from apparently adequate specificity, the proteinbinding method has several advantages over the fluorescence assay. In particular, it contains fewer as well as manually easier operations of both purification and quantitation, thus enabling twice as many samples to be run with the same labor and time, and it is at least five-fold more sensitive. These are not compelling reasons for investing in new and costly equipment in order to abandon a working fluorescence assay in favor of the protein-binding assay. However, investigators having access to radioactivity counters, or involved in the measurement of cortisol rather than or in addition to corticosterone, or those interested in measuring a number of steroids with the same basic procedure, would do well to give serious consideration to the gains and long-term future offered by the protein-binding technique.

\section{REFERENCES}

ANASTASSIADIS, P. A., \& COMMON, R. H. Some aspects of the reliability of chemical analysis. Analytical Biochemistry, 1968, 22 ,
409-423.

BEATTY, P. A. The effects of ACTH, adrenalectomy, and dexamethasone on the acquisition of an avoidance response in rats. Unpublished PhD dissertation, University of Wisconsin.

BOWMAN, R. E. Ultramicro method for nonconjugated 17-Hydroxycortico-steroids in one half milliliter of monkey or human plasma. Analy tical Biochemistry, 1967, 19, 166-176.

BOWMAN, R. E., \& De LUNA, R. F. Assessment of a protein-binding method for cortisol determination. Analytical Biochemistry, 1968, 26, 465.

EECHAUTE, W. A simple chromatographic technique for the determination of cortisol and corticosterone in plasma. Steroids, 1966, 8 , 633-654.

ELY, R. S., HUGHES, E. R., \& KELLEY, V. C. Studies of adnenal corticosteroids. I. Estimation of plasma corticosterone and cortisol. The Journal of Clinical Endocrinology and Metabolism, 1958, 18, 190-207.

FRANKEL, A. I., COOK, B., GRABER, J. W., \& NALBANDOV, A. V. Determination of corticosterone in plasma by fluorometric techniques. Endocrinology, 1967, 80, 181-194.

GLICK, D., von REDLICH, D., \& LEVINE, S. Fluorometric determination of corticosterone and cortisol in 0.02-0.05 milliliters of plasma or submilligram samples of adrenal tissue. Endocrinology, 1964, 74, 653-655.

HORTON, R., KATO, T., \& SHERINS, R. A. A rapid method for the estimation of testosterone in male plasma. Steroids, 1967, 10, 245-255.

JAMES, V. H. T., TOWNSEND, J., \& FRASER, R. Comparison of fluorimetric and isotopic procedures for the determination of plasma cortisol. Joumal of Endocrinology, 1967, 37, 28.

MURPHY, B. E. P. Some studies of the protein-binding of steroids and their application to the routine micro and ultramicro measurement of various steroids in body fluids by competitive protein-binding radioassay. The Joumal of Clinical Endocrinology and Metabolism, $1967,27,973-990$.

MURPHY, B. E. P. Binding of testosterone and estradiol in plasma. Canadian Journal of Biochemistry, 1968, 46, 299-302.

MURPHY, B. E. P., ENGELBERG, W., \& PATTEE, C. J. Simple method for the determination of plasma corticoids. The Journal of Clinical Endocrinology and Metabolism, 1963, 23, 293-300.

NIELSEN, E., \& ASFELDT, V. H. Studies on the specificity of fluorimetric determination of plasma corticosteroids ad modum de Moor \& Steeno. Scandinavian Joumal of Clinical and Laboratory Investigation, 1967, 20, 185-194.

PETERSON, R. E., KARRER, A., \& GUERRA, S. L. Evaluation of Silber-Porter procedure for determination of plasma hydrocortisone. Analytical Chemistry, 1957, 29, 144-149.

POLIDORA, V. J., \& BOWMAN, R. E. Psychochemistry. In J. B. Sidowski (Ed.), Experimental methods and instrumentation in psychology. New York: McGraw-Hill, 1966.

SOLEM, J. H., \& BRINCK-JOHNSEN, T. An evaluation of a method for determination of free corticosteroids in minute quantities of mouse plasma. Scandinavian Journal of Clinical and Laboratory Investigation, $1965,17,1.14$.

TARQUINI, B., \& TOCCAFONDI, R. Determinazione spettrofluorimetrica dei corticoidi plasmatici liberi. Lo Sperimentale, 1965, 115, 195-206.

YOSHIMI, T., \& LIPSETT, M. B. The measurement of plasma progesterone. Steroids, $1968,11,527-540$.

\section{ERRATUM}

PROKASY, W. F. Toward a complete analysis of GSR data. Behavior Research Methods and Instrumentation, 1969, 1 (3), 99-101-On page 100 the two figures appearing over the legends should be reversed. 